Universidad de Lima

Facultad de Comunicación

Carrera de Comunicación

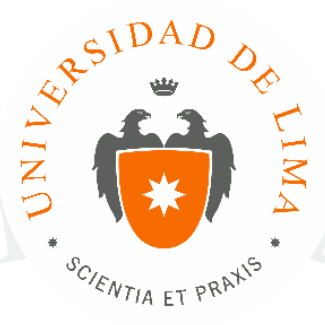

\title{
ANÁLISIS DE USABILIDAD DE UNA HERRAMIENTA VIRTUAL DE APRENDIZAJE: CASO ICPNA MALL
}

Trabajo de investigación para optar el Título Profesional de Licenciado en

Comunicación

\section{Ricardo Valle Ruiz}

Código 20101957

\section{Asesora}

Thelmy María del Carmen Mendoza Michilot

Lima - Perú

Abril de 2017 


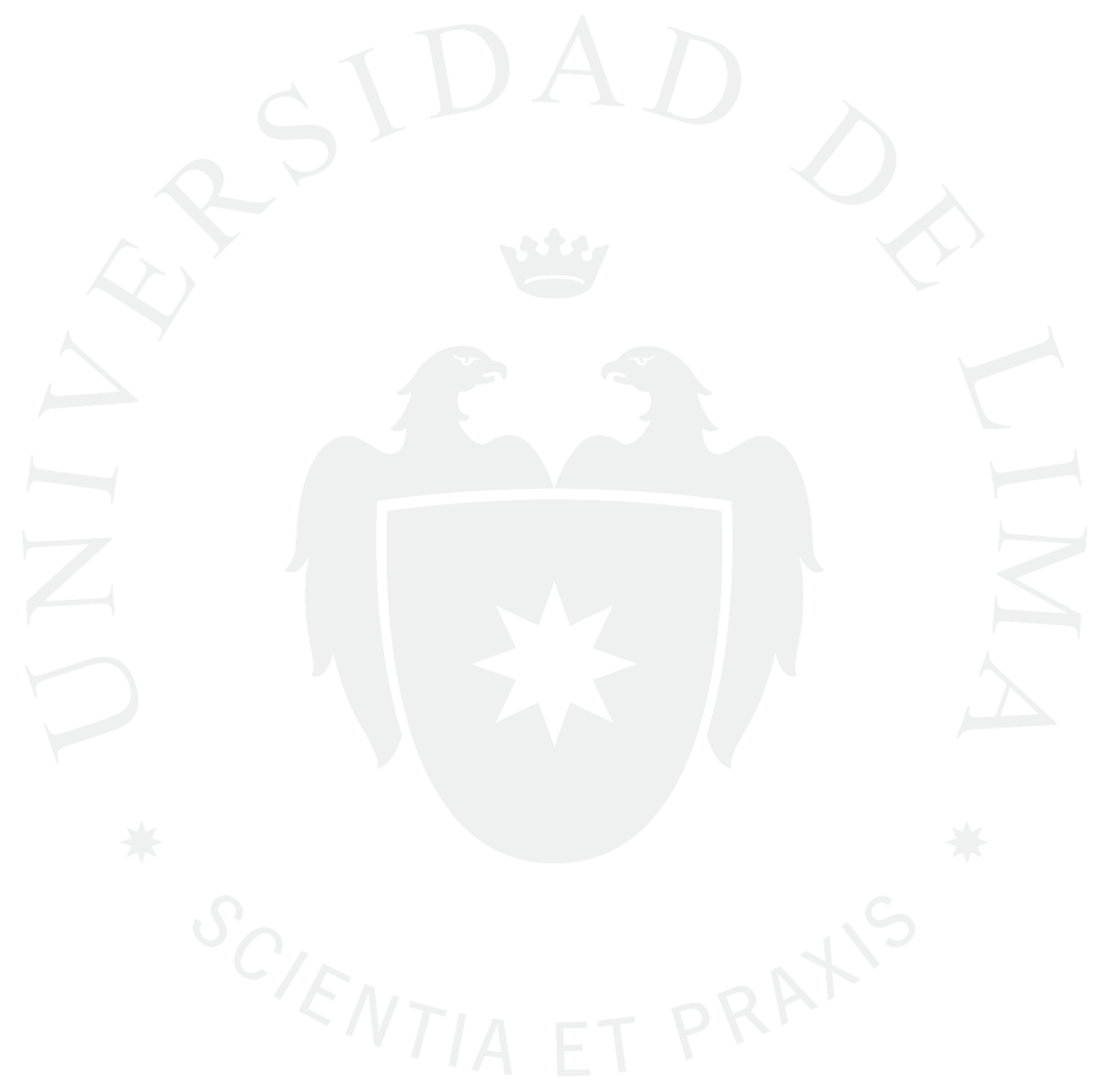


Análisis de usabilidad de una herramienta virtual de aprendizaje: caso ICPNA Mall 


\title{
RESUMEN
}

Las tecnologías de la información y la comunicación (TICs) han tenido un efecto transformador en el área del aprendizaje. En este estudio se evaluó la usabilidad percibida de una herramienta de formación virtual. Al tratarse de una solución de reciente creación y de acceso a través de la web, es necesario que se analice su usabilidad, un elemento importante que se debe tener en cuenta en cualquier proyecto de aprendizaje virtual. En este caso, se recogió la percepción de los alumnos para evaluar la herramienta y emitir recomendaciones que puedan enriquecer su experiencia. A través de entrevistas a profundidad y el análisis de la información obtenida, se pudo determinar qué características de la herramienta favorecen su usabilidad, así como las que la obstaculizan. Se reconoció la correspondencia que existe entre los contenidos de la herramienta con el currículo que conforma las clases presenciales, así como un diseño visual simple y fácil de entender. Sin embargo, se detectaron problemas con el desarrollo de las evaluaciones y la retroalimentación recibida.

\section{PALABRAS CLAVE:}

Percepción, satisfacción, TICs, usabilidad, utilidad.

\begin{abstract}
Communication and information technologies (CITs) have had a transforming effect in learning. This study evaluates the perceived usability of an e-learning tool. Because it is a recent solution and it is accessible through the web, it is necessary that its usability is analyzed since this is an important element that has to be taken into consideration in any eLearning project. In this case, students' perceptions were elicited in order to evaluate the tool and to produce recommendations that can enrich learners' experience. Through in-depth interviews and the analysis of the information, characteristics of the tool that increase and hinder its usability were drawn. The correspondence between contents and curricula for face-to-face classes, a simple and easy-to-understand visual design were recognized. Nevertheless, problems regarding the evaluation and feedback were detected.
\end{abstract}

\section{KEYWORDS}

Perception, satisfaction, CITs, usability, utility. 


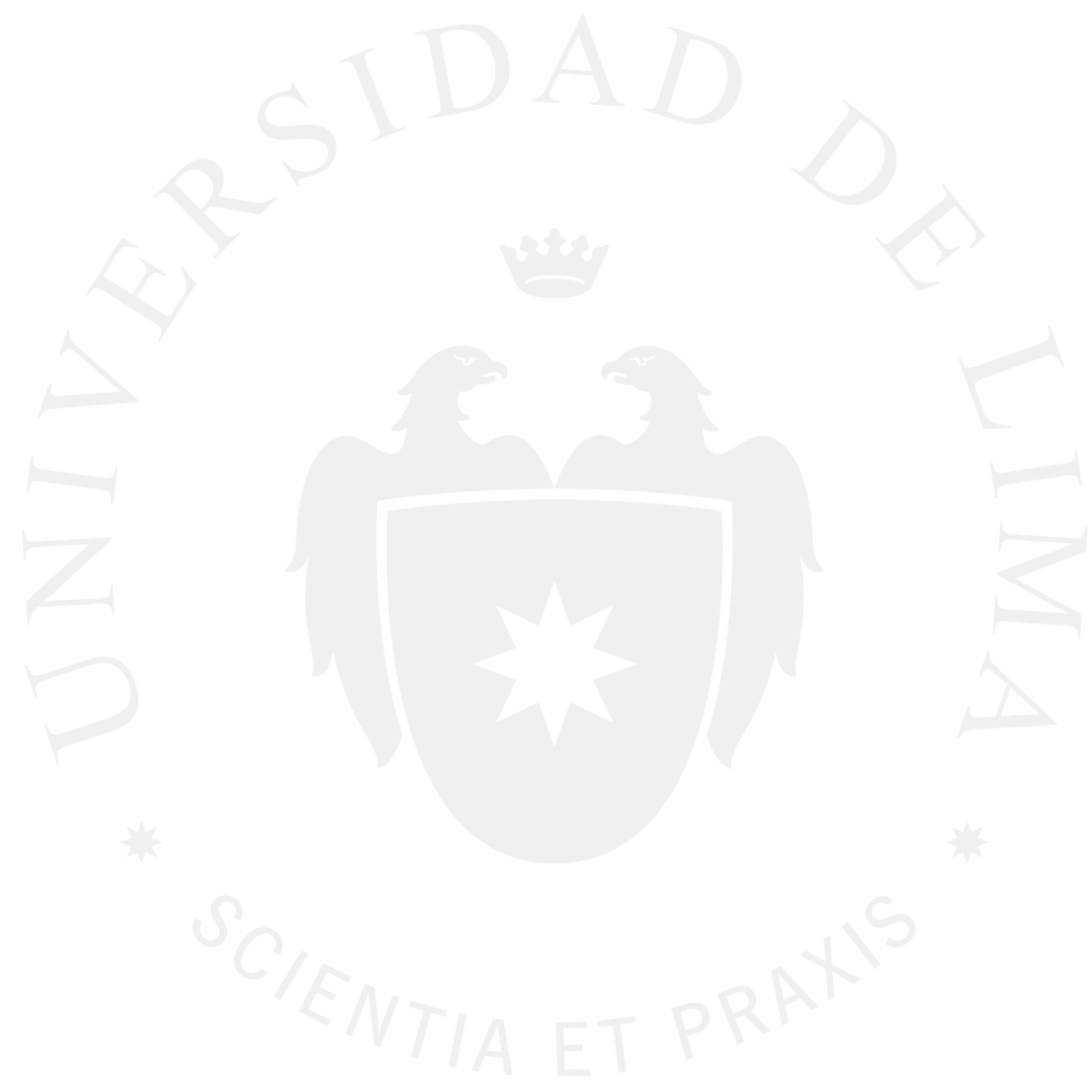




\section{INTRODUCCIÓN}

Las tecnologías de la información y la comunicación continúan incidiendo en diferentes ámbitos del quehacer humano, no solo como herramientas para facilitar ciertas labores, sino como generadoras de innovaciones disruptivas, ya que introducen un cambio importante y muchas veces radical en el ámbito en el que inciden (Christensen, 2007). El campo del aprendizaje de inglés como lengua extranjera no ha quedado fuera de este alcance. Los centros de idiomas más conocidos del mercado limeño cuentan con soluciones de educación virtual que hacen uso de internet para potenciar la enseñanza del idioma. En algunos casos, ofrecen soluciones de e -learning o aprendizaje cien por ciento virtual (Euroidiomas, 2017; Idiomas Católica, 2017), y en otros casos, con programas de b-learning o aprendizaje semipresencial, en el que se conjugan las clases virtuales con las sesiones cara a cara (Británico, 2017).

Dentro de este contexto, encontramos al Instituto Cultural Peruano Norteamericano (ICPNA) con su iniciativa ICPNA Mall, que se encuentra más alineada a la categoría de aprendizaje semipresencial. Esta herramienta provee a los alumnos con material adicional de refuerzo y consolidación de lo aprendido en clase. Este modelo, se encuadra en el constructivismo educativo, ya que favorece el uso de conocimientos previos para construir nuevo aprendizaje significativo, a través de la experiencia y el contacto directo con el material. (Tünnermann, 2011; Ertmer y Newby, 2013).

ICPNA Mall, al tratarse de una iniciativa relativamente reciente, puede admitir mejoras, sobre todo en ciertos aspectos relacionados a la experiencia de los alumnos. Entre ellos, la usabilidad es una característica crucial para asegurar una experiencia de usuario favorable, y positiva (Triacca et al., 2004; Ardito et al., 2004; Botturi et al., 2007).

\section{Usabilidad como Facilidad de Uso}

La norma ISO 9241 en su décimo primera parte explica la usabilidad como la magnitud en la que un producto puede ser utilizado por usuarios específicos para alcanzar ciertas metas con efectividad, eficiencia y satisfacción en un contexto específico de uso (Reyes y Libreros, 2011, p. 70). En el caso de las soluciones de aprendizaje virtual, los estudios de usabilidad se han centrado en gran parte en evaluar la facilidad de uso de la 
interfaz con la que interactúan los alumnos (Nielsen, 2003; Krug, 2000; Schneiderman, 1998).

La usabilidad en cursos virtuales o herramientas de e-learning y b-learning ha sido objeto de estudio de múltiples investigaciones. En general trabajos como el de Chandra y Yin (2009) o el de Davids, Chilkte y Halperin (2014) resaltan la importancia de aspectos funcionales y de diseño, como la navegabilidad, la consistencia del diseño visual, la funcionalidad de los elementos interactivos y la precisión de las instrucciones, para asegurar una adecuada usabilidad.

Es visible en estos casos que los estudios se han enfocado en criterios relacionados prioritariamente con el diseño de la interfaz con la que interactúa el alumno; no obstante, se deja de lado el contenido y lo que este implica para el aprendizaje. Ciertamente, aspectos que deberían ser importantes cuando se evalúan iniciativas educativas.

\section{Utilidad y Satisfacción}

A pesar de lo antes expuesto, se puede identificar otra rama de estudios que amplían el espectro de la usabilidad hacia variables más subjetivas y afectivas. En un estudio publicado en India que compara los cursos virtuales del Massachusetts Institute of Technology (MIT) en EEUU, la Visweswaraiah Technological University (VTU) en India y el Tokyo Institute of Technology (TITECH) en Japón, se determina que además de los criterios usuales para evaluar usabilidad, se debe también medir el nivel de utilidad que se proporciona a los usuarios cuando se trata de soluciones de aprendizaje (GhalibAIMasoudi y Chandrashekara, 2010).

Del mismo modo, Nielsen (2003) y la norma ISO 9241 dejan bastante claro que la satisfacción es un componente importante de la usabilidad. En ciertos casos se toma en cuenta la satisfacción con el diseño de la interfaz, pero también será posible evaluar la satisfacción del usuario con el contenido presentado o con los resultados obtenidos a partir del uso de la herramienta. En el caso de las soluciones de aprendizaje se puede analizar la satisfacción de los alumnos con el contenido educativo virtual.

Es importante recalcar que al medir la usabilidad, no se pretende evaluar la calidad académica del contenido, ni su efectividad metodológica como elemento de 
aprendizaje, ya que estos son aspectos netamente educativos que no están relacionados con los objetivos de este estudio.

\section{METODOLOGÍA}

El estudio se llevó a cabo en el mes de Setiembre de 2015, en el ICPNA, sede Miraflores. Para este fin se optó por una metodología cualitativa. A través de ella, se pretende describir la percepción de los estudiantes que usan la herramienta de aprendizaje virtual en cuestión. En este caso se toman en cuenta las percepciones y subjetividades de los participantes al momento de interactuar con dicha herramienta por lo que el estudio se ubicaría dentro de un diseño fenomenológico (Hernández, Fernández y Baptista, 2006).

\begin{tabular}{|l|l|}
\hline Metodología & Cualitativa \\
\hline Tipo de Estudio & Estudio de caso \\
\hline Técnica & Entrevista a profundidad \\
\hline Herramienta & Guía de entrevista estructurada \\
\hline Universo & Alumnos del nivel Básico 1 \\
\hline (sede Miraflores) \\
\hline Muestra & 15 alumnos voluntarios \\
\hline Unidad de Análisis & Percepciones de estudiantes \\
\hline Muestreo & No probabilístico, por conveniencia \\
\hline Modelo de Investigación & Cuestionario de Zaharias (2009) \\
\hline
\end{tabular}

Tabla 1: Ficha metodológica

Por otro lado es importante definir que este es un estudio de caso, enfocado en el uso de una herramienta virtual de aprendizaje y que toma varias experiencias de los 
usuarios a profundidad. La unidad de análisis en este caso es la percepción de cada alumno con respecto a la usabilidad integral de la herramienta de aprendizaje.

En este caso se decide usar la técnica de entrevista a profundidad con cada uno de los participantes en el estudio.

Para elegir la muestra, se usó un muestreo no probabilístico por conveniencia (Hernández, Fernández y Baptista, 2006). Se realizó una convocatoria a estudiantes del primer nivel (Básico 1) de estudios de la sede Miraflores del ICPNA. Quince voluntarios se registraron para tomar lugar en la investigación. El grupo era diverso: estaba compuesto por individuos de ambos géneros, de diversas ocupaciones, entre los 18 y 30 años de edad.

Como modelo de investigación, se tomó como referencia un cuestionario usado por Zaharias (2009) en su estudio Developing a Usability Evaluation Method for eLearning Applications: Beyond Functional Usability. Este cuestionario tomaba en cuenta aspectos afectivos para evaluar la usabilidad de materiales de aprendizaje virtual. No obstante, no se utilizaron todas las secciones del cuestionario de Zaharias. Las secciones de Accesibilidad e Interactividad se unieron con otros aspectos en una sección de Funcionalidad. Se dejaron de lado las secciones de Motivación para Aprender o Autoevaluación. Sin embargo, se agregaron los ejes de Utilidad y Satisfacción para responder a los objetivos de este estudio.

La adaptación resultó en la herramienta usada para este trabajo: una guía de entrevista estructurada separada en tres ejes que responden a los objetivos del estudio: Facilidad de Uso, Utilidad y Satisfacción. El eje de facilidad de uso se divide en cinco atributos, y tiene como propósito recoger la información que regularmente se toma en cuenta para evaluar la usabilidad funcional de una herramienta. Evalúa el diseño visual, funcionalidad, soporte, navegabilidad y facilidad de uso general. El eje de Utilidad buscaba obtener información referente a qué tan útiles eran los contenidos vertidos en la herramienta de aprendizaje para los alumnos. Analiza atributos de contenido, evaluación, retroalimentación y utilidad general. Finalmente, el eje de satisfacción intenta conocer qué tan satisfechos están los usuarios con la herramienta y sus contenidos. 


\begin{tabular}{|c|c|c|}
\hline \multirow{10}{*}{ Usabilidad integral } & \multirow{5}{*}{ Facilidad de uso } & Diseño visual \\
\hline & & Funcionalidad \\
\hline & & Soporte \\
\hline & & Navegabilidad \\
\hline & & Facilidad de uso general \\
\hline & \multirow{4}{*}{ Utilidad } & Contenido \\
\hline & & Evaluación \\
\hline & & Retroalimentación \\
\hline & & Utilidad general \\
\hline & Satisfacción & Satisfacción general \\
\hline
\end{tabular}

Tabla 2: Matriz de la herramienta

\section{RESULTADOS}

\section{Facilidad de uso}




\subsection{Diseño visual}

\begin{tabular}{|l|c|}
\hline $\begin{array}{l}\text { Descripción del atributo: } \\
\text { Diseño visual }\end{array}$ & $\begin{array}{c}\text { Número de } \\
\text { alumnos }\end{array}$ \\
\hline Comprensible & 10 \\
\hline Adaptable (idiomas) & 8 \\
\hline Agradable & 4 \\
\hline Enfático & 3 \\
\hline Opaco & 3 \\
\hline Aburrido & 1 \\
\hline Serio & 1 \\
\hline
\end{tabular}

Tabla 3: Resumen de atributo: Diseño visual

La mayoría de los entrevistados consideran que el diseño es comprensible. "El diseño es fácil de entenderlo (sic)..." ( $\left.\mathrm{AP}^{1}\right)$. "Todo está ordenado y acorde a lo avanzado...” (RA). "El diseño se podía entender con facilidad...” (LG).

Más de la mitad indicaron que el diseño es adaptable, en el sentido en que pueden cambiar de idioma en ciertas pantallas (Ver Figura 1). "Si estuviera todo en inglés, no entendería nada. Tendría que estar buscando en otro lado y luego volver a la página" (AP). "Es interesante porque te dan el texto y lo puedes traducir al español, lo cual es útil porque a veces no entiendes algo y pones traducir, y eso te ayuda a comprenderlo..." $(\mathrm{AC})$.

\footnotetext{
${ }^{1}$ Se han usado las iniciales de los entrevistados en lugar de sus nombres completos para mantener
} su anonimato. 




Figura 1: Una pantalla de presentación de lección

También indicaron que el diseño enfatiza los contenidos que deben ser aprendidos. "las palabras más importantes como que la escriben de otra manera... las palabras que tienes que aprender están en otro color..." (HM). "Hay palabras en rojo que te facilitan qué clase estás haciendo...” (AP).

Expresaron además que el diseño era agradable. "Los colores son agradables..." (AC). "El diseño me parece más o menos agradable...” (CV).

Sin embargo, algunos indicaron que era aburrido. "Pienso que el diseño visual es algo aburrido. Siento que es muy plano. Tampoco debe ser muy ostentoso, pero pienso que deberían haber un poco más de diseño, pero no tanto..." (VC).

Se expresó también que el diseño era serio pero permitía concentrarse en el contenido. "El diseño es algo más serio, algo que no te desconcentra. Te tiene atado a lo que vas a responder y no hay distracciones...” (HM). Asimismo, se indicó que el diseño era opaco. "Para mí es muy opaco. Usan el gris, otro color medio ocre. No sé para mí es muy opaco. Para mí hay unos colores que te ayudan a estudiar..." (AP). 


\subsection{Funcionalidad}

\begin{tabular}{l|c}
\hline $\begin{array}{l}\text { Descripción del atributo: } \\
\text { Funcionalidad }\end{array}$ & $\begin{array}{c}\text { Número de } \\
\text { alumnos }\end{array}$ \\
\hline Funcional y Consistente & 15 \\
\hline Descarga rápida & 9 \\
\hline Descarga lenta & 2 \\
\hline Descarga variable & 2 \\
\hline
\end{tabular}

Tabla 4: Resumen de atributo: Funcionalidad

Se reconoció la correcta funcionalidad de los elementos interactivos de la herramienta (botones, vínculos) y su consistencia en el diseño para poder ser reconocidos intuitivamente y con rapidez. "Todos los botones son iguales, solo cambia el texto..." (AC). "Estaban encerrados en rectángulos, bien marcados, bien resaltantes, bien grandes..." (YR).

Se indicó que los contenidos en la herramienta cargan de forma rápida. "cargó en dos segundos porque tienen internet rápido... en mi casa se demoró 5 segundos... Normal porque ya estoy acostumbrado a que las cosas carguen...” (VC). Por otro lado, algunos indicaron que la carga era lenta. "En casa, nunca cargó. Eso debería solucionarse. Esperé casi tres minutos. Lo volví a intentar y fueron tres minutos de nuevo..." (LI). Otros señalaron que la velocidad de carga depende de dónde se conecten. "Demoró casi un minuto o a veces menos... creo que depende del internet, de los megas que tengas." (YR).

\subsection{Soporte}

\begin{tabular}{|l|c|}
\hline $\begin{array}{l}\text { Descripción del atributo: } \\
\text { Soporte }\end{array}$ & $\begin{array}{c}\text { Número de } \\
\text { alumnos }\end{array}$ \\
\hline Inexistente & 15 \\
\hline No necesita manual & 8 \\
\hline Necesita manual en texto & 3 \\
\hline Necesita video tutorial & 3 \\
\hline
\end{tabular}

Tabla 5: Resumen de atributo: Soporte

Los participantes señalaron no haber encontrado información de soporte en la herramienta. No existe algo que les indique con quién comunicarse en caso de tener un 
problema o consulta. "No me decía con quién hablar si tenía una pregunta, Había un ejercicio que no entendía. No sabía qué hacer aunque también arriba me explicara qué tenía que hacer en español. Solamente me decía completar y corregirlo, pero no... o sea veía qué cosa se podía corregir o trataba de buscar a alguien en internet supuestamente... porque a veces hay páginas en internet del ICPNA o de otro instituto como que tienes alguien más a tu lado. Como que vas a su página, le preguntas y te dan respuesta al toque y tú sigues, continúas..." (AP). "No aparece nada de eso, pero supongo que se ve con el profesor" (LI).

Algunos participantes indicaron que no era necesario proveer a los alumnos de un manual de uso. "No es necesario un manual. O sea, es bien accesible... es fácil de manejar, de explorar..." (YR).

Sin embargo, otros entrevistados refirieron que es necesario un manual en formato de texto. "Es necesario para algunas cosas. Por ejemplo hoy día, aparecía tres chicos y sus datos personales, y para completar. Y luego seguía el de la chica. Y completé bien, pero me salía mal y no entendía porque estaba mal. Y hasta ahora no entiendo porque estaba mal si toda la información estaba correcta. Así que seguro era por un punto o una mayúscula, pero yo no sabía por qué estaba mal...” (CR)

Otros señalaron que debería existir un manual a manera de video tutorial. "Quizás un video rápido de un minuto o treinta segundos. De cómo usar la herramienta como darle clic y eso, algo rápido..." (VC)

\subsection{Navegabilidad}

\begin{tabular}{|l|c|}
\hline $\begin{array}{l}\text { Descripción del atributo: } \\
\text { Navegabilidad }\end{array}$ & $\begin{array}{c}\text { Número de } \\
\text { alumnos }\end{array}$ \\
\hline Clara e intuitiva & 15 \\
\hline Progreso visible & 11 \\
\hline Progreso inexistente & 2 \\
\hline Números de pregunta muy pequeños & 2 \\
\hline
\end{tabular}

Tabla 6: Resumen de atributo: Navegabilidad

Los entrevistados señalaron que la navegación es clara e intuitiva. Todos conocen qué acciones son desencadenadas con los botones "Back" (Atrás) y "Next" 
(Siguiente) de cada pantalla. "Podía retroceder yendo atrás o Back. Había un botón en la herramienta para retroceder y para avanzar..." (RA). "Navegaba con Next y con Back" (VC).

Mencionan que sabían en qué parte del contenido se encontraban en todo momento, por lo tanto estaban informados de qué hacer luego o cuando regresaran a la herramienta en otra oportunidad. La herramienta provee la capacidad de continuar en donde el alumno detuvo su avance automáticamente. Es decir, la herramienta "recuerda" y sitúa al usuario en dónde se quedó. “....al costado sale un porcentaje y si lo has hecho bien. Cuando por ejemplo, lo dejé ayer, yo me acordaba dónde me quedé, pero cuando lo abrí hoy, sí salía dónde me había quedado... aparece un check verdecito en lo que ya has hecho y dentro de un ejercicio, sí aparece donde te habías quedado" (CR). "Al costado izquierdo decía dónde voy en el avance..." (JV).

Sin embargo, algunas alumnas no se percataron de ninguna indicación que les diera su progreso. "No, eso sí no salía [el progreso]. Solamente que en la práctica marcaba la respuesta y al final te salía cuántas son tus respuestas buenas y esas cosas...” (KS). "No he visualizado eso... No vi progresos ni alguna manera de ver cuántas preguntas faltan..." (YR).

Ciertos alumnos identificaron que en las evaluaciones se mostraba el número de pregunta a manera de progreso, pero era casi imperceptible. "Sí vi que decía 6 de 8 pero muy pequeñito..." (VC). "Habían unos números de las preguntas pero muy pequeños..." (LI).

\subsection{Facilidad de uso general}




\begin{tabular}{|l|c|}
\hline $\begin{array}{l}\text { Descripción del atributo: } \\
\text { Facilidad de uso general }\end{array}$ & $\begin{array}{c}\text { Número de } \\
\text { alumnos }\end{array}$ \\
\hline Muy fácil de usar & 6 \\
\hline Fácil de usar & 6 \\
\hline Más o menos fácil de usar & 1 \\
\hline Difícil de usar al inicio & 1 \\
\hline Algo difícil de usar & 1 \\
\hline
\end{tabular}

Tabla 7: Resumen de atributo: Facilidad de uso general

En general, los participantes consideran que la herramienta es de fácil uso. Algunos describen la herramienta como muy fácil de usar. Otros indican que es fácil de usar. Un número reducido indicó que la herramienta es más o menos fácil de usar, difícil de usar y un poco difícil de usar. Los alumnos que resaltan la facilidad de uso hacen referencia a la facilidad del diseño y la notoriedad de los elementos interactivos.

\section{Utilidad}

\subsection{Contenido}

\begin{tabular}{|l|c|}
\hline $\begin{array}{l}\text { Descripción del atributo: } \\
\text { Contenido }\end{array}$ & $\begin{array}{c}\text { Número de } \\
\text { alumnos }\end{array}$ \\
\hline Correspondiente & 15 \\
\hline Nivel de inglés comprensible & 13 \\
\hline Refuerzo & 12 \\
\hline Expansión & 1 \\
\hline Adaptable (idioma) & 2 \\
\hline Nivel de inglés inadecuado & 1 \\
\hline Faltan ejemplos & 1 \\
\hline
\end{tabular}

Tabla 8: Resumen de atributo: Contenido

Unánimemente, se considera que los contenidos de la herramienta corresponden a lo que los alumnos ven en el aula, de manera que les sirve de repaso y expansión de los temas aprendidos. "Era muy parecido. Casi todo lo que habíamos hecho en la clase estaba en... en la computadora. Algunas cosas nomás variaba pero eran las mismas...” (AH) "Es igual a lo que vemos en clase..." (CV) 
Refieren que el nivel de inglés usado es comprensible para el nivel de los alumnos. "[El nivel de inglés] estaba bien. Hubieron cosas que no entendía pero fueron poquísimas..." (LG). "Me pareció que está bien. La mayoría de cosas si logré entender..." (CV).

Algunos señalan que el contenido les sirve como refuerzo a sus clases. "Todo lo que aprendemos en el salón está en la computadora y como que te ayuda a reforzar lo que has aprendido en el día..." (AH). "Me va ayudando con cada tema o cada palabra me va diciendo que es lo que tengo que hacer. O si no, me va guiando con el tema que yo no sé, puedo repasarlo..." (RA).

Además, se dijo que servía para expandir lo que se vio en clase. "Me dan más porque a veces la explicación del profesor como que se corta o queda corto el tiempo y ahí te dice qué hacer..." (HM).

Resaltaron la capacidad de cambiar el idioma del contenido en algunas pantallas como algo beneficioso. "Era fácil y las partes que estaban en inglés que no podía entender las podía poner en español y así las entendía más..." (AH). "Bien porque el español como que te ayuda un poco. Si solo estuviera en inglés, tengo entendido que no todo debería estar en inglés sino que hay palabras exactas que ya vimos en la clase y eso con eso me ayuda..." (AP).

Sin embargo, en un caso, se indicó que el nivel de inglés era poco comprensible. "Habían cosas que no entendía... tenía que preguntar o buscar en el traductor..." (AC).

Finalmente, una alumna señaló que hacían falta más ejemplos. "No me parece la manera adecuada [de presentar la gramática] porque al menos deberían haber dos ejemplos o un poco más..." (AP).

\subsection{Evaluación}

\begin{tabular}{l|l} 
Descripción del atributo: & Número de \\
Evaluación & alumnos
\end{tabular}




\begin{tabular}{|l|c|}
\hline Refuerzo & 11 \\
\hline Preguntas insuficientes & 9 \\
\hline Preguntas suficientes & 5 \\
\hline Instrucciones comprensibles & 4 \\
\hline Correspondientes & 2 \\
\hline
\end{tabular}

Mencionaron que las evaluaciones existentes en la herramienta les sirven como refuerzo para sus clases. "[Me ayudan] demasiado porque ves lo que has visto en un día o en un día anterior. Lo repasas y repasas, puedes ver en que te equivocas..." (AC). "Es como un complemento. Y de hecho a veces no ves mucho el libro, pero ves esta herramienta que te explica de manera sencilla. Es como un repaso...” (VC).

Algunos señalaron que les parece insuficiente el número de preguntas usado en estas evaluaciones. "Es muy poquito. En uno solo había 3 preguntas, en otro 8. Por cada tema deberían haber $15 \ldots$... (AP). "Deberían haber más problemas para poder tener más dificultad y así poder tener más tiempo para ejercitar la mente. Un número adecuado sería unos 50 más o menos...” (AC).

Mientras que otros las consideran suficientes. "Sí es suficiente para poder seguir avanzando. Si te ponen un montón te puedes aburrir de lo mismo..." (CR). "Sí me pareció una cantidad razonable..." (VC). "Para mí estaba bien..." (LI).

Algunos participantes señalan que las instrucciones de las evaluaciones eran comprensibles. "hay unas palabras que salen arriba en inglés y luego en español. Si está todo en inglés, no lo voy a entender y en la parte inferior está en español y así si lo pude entender y aparte que hay audios... No sé inglés, pero cuando hay audios y partes que se entienden un poco sí puedo responder sola..." (AH).

Algunos entrevistados resaltaron que las evaluaciones corresponden al currículo de las clases presenciales. "los quiz se basan en cada tema que voy avanzando poco a poco..." (RA). "Es algo relacionado a las clases que voy avanzando y veo ejercicios que son muy parecidos a las clases que tengo a diario en el ICPNA..." (AC).

\subsection{Retroalimentación}

\begin{tabular}{l|l} 
Descripción del atributo: & Número de \\
Retroalimentación & alumnos
\end{tabular}




\begin{tabular}{|l|l|}
\hline No da respuestas correctas & 8 \\
\hline Comentarios positivos o de aliento & 6 \\
\hline Útil & 5 \\
\hline Varios intentos & 4 \\
\hline Pistas & 3 \\
\hline Confusa & 3 \\
\hline Respuestas al final & 1 \\
\hline \multicolumn{2}{|c|}{ Tabla 10: Resumen de atributo: Retroalimentación }
\end{tabular}

Los participantes señalaron que el sistema no brindaba las respuestas correctas cuando ellos no las sabían. "Eso si no me lo da. No me da la respuesta. Simplemente me pasa a otra pregunta..." (AH). "Si no sabes la respuesta correcta el sistema no te la da ni siquiera al final de la prueba. Había algunas pruebas que te ponían como una ayuda. Pero no en todas..." (AI).

Indicaron la presencia de comentarios positivos cuando hacían bien los ejercicios o mensajes de aliento cuando se equivocaban. "Si te equivocas te dice "Respuesta incorrecta, inténtalo de nuevo" Me parece que son tres veces y si te equivocas ya te dice para que pases al siguiente..." (AI). "Aparece un ícono con un mensaje que dice incorrecto de un color diferente que es correcto. De color amarillo..." (LI).

Señalaron que la retroalimentación es útil para ellos. "Me ayudan bastante, en que aprendo las cosas que no sabía..." (CV). "Me ayuda a sacar una alternativa y tengo más oportunidad de darle a la respuesta correcta..." (AC).

Otros señalaron que tenían hasta tres intentos para corregir sus errores. "Vuelvo a intentar y lo vuelvo a intentar..." (AH). "Si me equivoco, puedo borrar con la tecla, pero creo que cuando voy en el tercer intento, ya no puedo hacer clic, ya no puedo borrarla..." (HM).

Algunos entrevistados recalcaron la importancia de la retroalimentación que a manera de pistas les hacía saber la respuesta correcta. "Había algunas pruebas que te ponían como una ayuda..." (AI). "No me ayudaba con la respuesta exactamente. Me decía algún ejemplo o en que me estoy equivocando, a qué se refiere la pregunta... prefiero que me ayude en lugar que me dé la respuesta correcta..." (RA). 


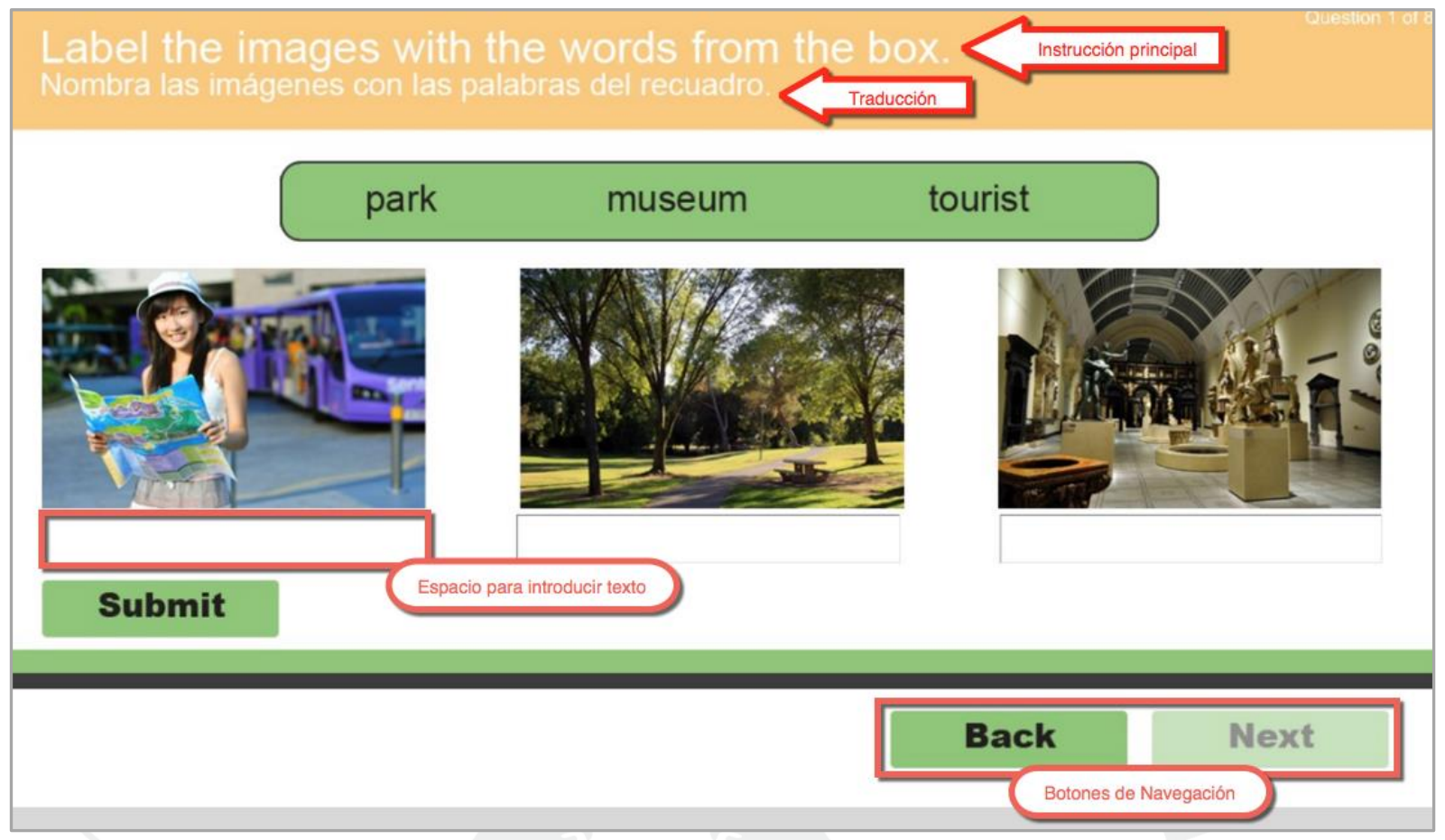

Figura 2: Una pantalla de evaluación con tres ítems para completar

Otros indicaron que en algunas pantallas de ejercicios tenían que hacer todo bien para que se considere correcto, ya que el sistema no lograba corregir ítem por ítem, entonces si decía que se habían equivocado, no había manera de saber en qué ítem se había cometido el error (Ver Figura 2). "Por ejemplo, hay un ejercicio en el que hay varios cuadros, y en esos cuadros tienes que llenar. Entonces llenas y cuando haces clic para ver si está correcto, te sale "inténtelo" pero no te dice cuál está mal. Ese es el problema..." (KS). "Pero si no lo hacías no te decía qué estaba mal. Es que yo recuerdo que había un cuadro en el que había tres imágenes, y había para llenar en la parte de abajo. Entonces te decía "inténtalo de nuevo", "inténtalo de nuevo", pero no te decía cuál estaba mal..." (VC).

Solo una alumna se percató de que al finalizar la evaluación podía regresar a ver todas las respuestas correctas y las correcciones correspondientes. "Al último, cuando ya salía tu porcentaje ahí salía para ver tus respuestas y te decía para ver cuáles eran las correctas..." (CR).

\subsection{Utilidad general}

\begin{tabular}{l|c} 
Descripción del atributo: & $\begin{array}{c}\text { Número de } \\
\text { alumnos }\end{array}$ \\
\hline Utilidad general &
\end{tabular}




\begin{tabular}{l|c} 
Muy útil & 10 \\
\hline Útil & 5 \\
\hline
\end{tabular}

Tabla 11: Resumen de atributo: Utilidad general

Todos los participantes expresaron que la herramienta les parece útil o muy útil. "Es muy buena me ha ayudado bastante para poder aprender más el inglés..." (AC). “¿Del uno al diez? Diría que como toda herramienta de aprendizaje yo le pondría un 10. Porque es un tema de aprendizaje..." (VC). "Me parece útil para aprender...” (CV). "Sí me parece útil porque me dice en que estoy bien y en qué puedo mejorar...” (AI).

\section{Satisfacción}

\subsection{Satisfacción general}

\begin{tabular}{|l|c|}
\hline $\begin{array}{l}\text { Descripción del atributo: } \\
\text { Satisfacción general }\end{array}$ & $\begin{array}{c}\text { Número de } \\
\text { alumnos }\end{array}$ \\
\hline Muy satisfechos & 9 \\
\hline Algo satisfechos & 4 \\
\hline Neutral & 1 \\
\hline Algo insatisfecho & 1 \\
\hline
\end{tabular}

Tabla 12: Resumen de atributo: Satisfacción general

La mayoría indicó que se encontraba muy satisfecha con la herramienta. "Bien, bien, pero sí es una buena opción a poder seguir practicando. Fuera de que tengas un libro, el libro es más como guía de clase y esta aplicación o esta herramienta es como para ya darle un poco más de uso, sacarle más provecho con los audios y los otros ejercicios que hay..." (LI). "me siento muy bien porque me ayuda a mí personalmente a practicar con esta herramienta..." (YR). Además reconocieron que recomendarían la herramienta a otros alumnos y que les gustaría seguir usándola en otros cursos.

Otros dijeron estar algo satisfechos. "Más o menos. Porque como dije me gustaría que fueran más preguntas. Con pocas preguntas no se podría evaluar bien..." (AI). “Ahora sí me siento satisfecho pero la primera vez que la abrí no. Ahora sé un poco más de inglés. Antes usaba el traductor para entender..." (CV). 
Uno mantuvo una posición neutral. "Ahí sí hay varias cosas que influyen. El botoncito, lo del tema visual. Yo le pondría un 5. Y un cinco es bastante...” (VC).

Un entrevistado señaló estar algo insatisfecho. "A veces como que no tan satisfecha porque no sé exactamente la respuesta y tengo que salir a buscar o preguntarle al profesor..." (AP). 
A partir del análisis de los datos recogidos se puede considerar que el grueso de los usuarios consultados coincide en señalar a la herramienta como un elemento de una adecuada usabilidad integral, ya que se la califica más frecuentemente como fácil de usar, útil y satisfactoria. Sin embargo, existen también, en más baja frecuencia, los comentarios sobre atributos que reflejan la percepción de una disminuida usabilidad integral.

En general, los usuarios consideran que la herramienta es fácil de usar. Esta percepción está estrechamente ligada a la presencia de un diseño visual comprensible, consistente, adaptable y agradable; a la funcionalidad de los elementos interactivos; y a la presencia de una navegabilidad intuitiva y clara.

El alumno puede comprender la interfaz rápidamente y se acostumbra a encontrar los botones y sus funcionalidades fácilmente porque los elementos del diseño no varían de lugar o aparecen erráticos en las diferentes pantallas. Asimismo, el contenido se adapta ofreciéndole al alumno la opción de cambiar el idioma en ciertas secciones, lo que les ayuda a comprender mejor dado su nivel de competencia en la lengua que están aprendiendo. De acuerdo a los datos recogidos, la estética del diseño es un elemento importante a considerar, ya que un diseño aburrido o muy opaco puede desmotivar a los usuarios haciendo más difícil usar la herramienta. En general, los alumnos que respondieron que el diseño visual les parecía aburrido, encontraron más dificultad en el uso de la herramienta que el resto. Esto refuerza lo expuesto por Nielsen (2003), Krug (2000) y Schneiderman (1998) cuando señalan que la facilidad de uso depende directamente del diseño al tener este un impacto integral sobre la interfaz con la que se relaciona el usuario. Un diseño más atractivo impacta positivamente sobre la facilidad de uso (Davids, Chilkte y Halperin, 2014).

Además, los botones y otros elementos interactivos funcionan correctamente cada vez que son utilizados. Su funcionalidad también es de rápida respuesta y consistente a través de las diferentes pantallas de la herramienta. Asimismo, se usan elementos conocidos en el bagaje tecnológico que traen consigo los usuarios, de esta forma se usan sus conocimientos previos para favorecer un aprendizaje significativo como lo propone el constructivismo (Tünnermann, 2011; Mvududu y Thiel-Burgess, 2012). Por ejemplo, se encuentran con botones de Back y Next como en ciertas aplicaciones recientes de diversas plataformas o reconocen figuras icónicas que les ayudan a descifrar la funcionalidad de un botón, como el de audio que es un pequeño 
parlante. Esto es una gran ventaja, ya que como comprobaron Davids, Chilkte y Halperin (2014), incluir elementos que promueven el reconocimiento tiene un efecto positivo sobre la facilidad de uso.

Adicionalmente, la navegación es clara e intuitiva ya que los botones que permiten que el usuario se mueva dentro del contenido están posicionados de la siguiente manera: "Next" (siguiente) al lado derecho de la parte inferior de la pantalla; y "Back" (atrás) al lado izquierdo del anterior. Esta es una disposición similar a la usada en otras plataformas virtuales por lo que los alumnos que hacen uso de ellas, tienen cierto preconocimiento de cómo moverse por el contenido. Según GhalibAI-Masoudi y Chandrashekara (2010) la navegación sencilla y fácil de entender es un elemento importante de la facilidad de uso.

No obstante, también existen atributos que degradan la facilidad de uso en la experiencia de ciertos estudiantes. Los factores que no apoyan a que el contenido sea más fácil de usar son la carencia de soporte externo y la ausencia de un manual o tutorial para quienes más lo necesitan.

El contenido no brinda información de soporte para los usuarios. Es decir, ellos deben relacionarse con los contenidos de manera completamente autónoma, y en la eventualidad de una duda o problema, no tienen la oportunidad de hacer llegar su pregunta o comentario a los administradores del contenido. Simplemente, pueden consultar a su profesor cuando se encuentren en el aula. Esto no es un problema para muchos de ellos, pero considerando la diversidad de los estudiantes, existen casos en los que contar con un soporte adicional o alguien con quien consultar sobre el uso de la herramienta son características esenciales para alcanzar un uso adecuado.

Aunque la mayoría de los participantes indica que no es necesario un manual o tutorial -lo que concuerda con la idea de Benbunan-Fich (2001) cuando indica que el usuario no debe necesitar instrucciones para hacer uso de la herramienta para considerarla fácil de usar-, sí encontramos casos en los que ciertos alumnos necesitan de una guía precisa para poder interactuar con la herramienta de manera correcta. Esto podría deberse a la poca experiencia con plataformas similares o factores culturales aunque mayor precisión sería materia de un estudio futuro. Como mencionan Reyes y Libreros (2011), las guías segmentadas que precisan las acciones del usuario son altamente recomendadas en herramientas o aplicaciones de aprendizaje virtual. 
Con respecto a la utilidad, es evidente que todos los participantes consideran que la herramienta es útil por tratarse de material educativo. Esto impacta positivamente la usabilidad integral, como lo explica Notess (2011) la utilidad y la usabilidad están directamente correlacionadas. Los atributos que apoyan esta percepción en el caso analizado son la correspondencia del contenido presentado con el estudiado en las aulas y la posibilidad de hacer uso de esta herramienta como material de reforzamiento.

El contenido está sumamente adaptado al currículo usado para el curso presencial. Esto se debe a que fue creado basado en ese currículo y considerando los puntos tocados en el curso. Se reciclan las estructuras gramaticales, los ítems de vocabulario y las estrategias de comprensión auditiva y lectora que los usuarios aprenden en sus clases. Esta disposición de contenidos, refuerza la idea de que el ICPNA Mall está enmarcado en el constructivismo, ya que el aprendiz parte de los conocimientos que dispone (los adquiridos en el aula) para poder edificar sobre ellos el nuevo conocimiento, y relacionar ambos para que sea significativo (Araya, Alfaro y Andonegui, 2007; Guilar, 2009). En el estudio de GhalibAI-Masoudi y Chandrashekara (2010), se consideró que los contenidos mejor alineados con el currículo de los alumnos son considerados más útiles.

Este atributo es tan notorio que los alumnos consideran la herramienta como una fuente de reforzamiento de lo que aprenden en el aula. Ciertos estudiantes necesitan un poco más de explicación y práctica para algunos temas. La herramienta les da la posibilidad de satisfacer esa necesidad sin tener que coordinar una cita con el profesor o destinar tiempo de otra clase para el repaso. En concreto, el ICPNA Mall les provee una forma novedosa de repasar y ampliar su conocimiento, que no sería posible sin el uso de las nuevas tecnologías. Esto eleva a la herramienta como una innovación disruptiva en el proceso de aprendizaje, según lo propuesto por Christensen (1997).

Sin embargo, existen atributos que disminuyen la utilidad de la herramienta como el hecho de que las evaluaciones son muy cortas y en ciertos casos no cubren las expectativas de los alumnos en cuanto a número de ejercicios de práctica. También impacta negativamente el hecho de que en ciertos ejercicios no queda claro cuál es la respuesta correcta cuando el alumno comete un error.

Existen usuarios que desean practicar con el material en preguntas o ejercicios típicos como de opción múltiple o llenando espacios en blanco. El promedio de ocho 
ejercicios por tema que se encuentran en la herramienta (incluso a veces son menos) no son percibidos como suficientes por algunos alumnos. Ellos desean una mayor cantidad para sentir que realmente están practicando.

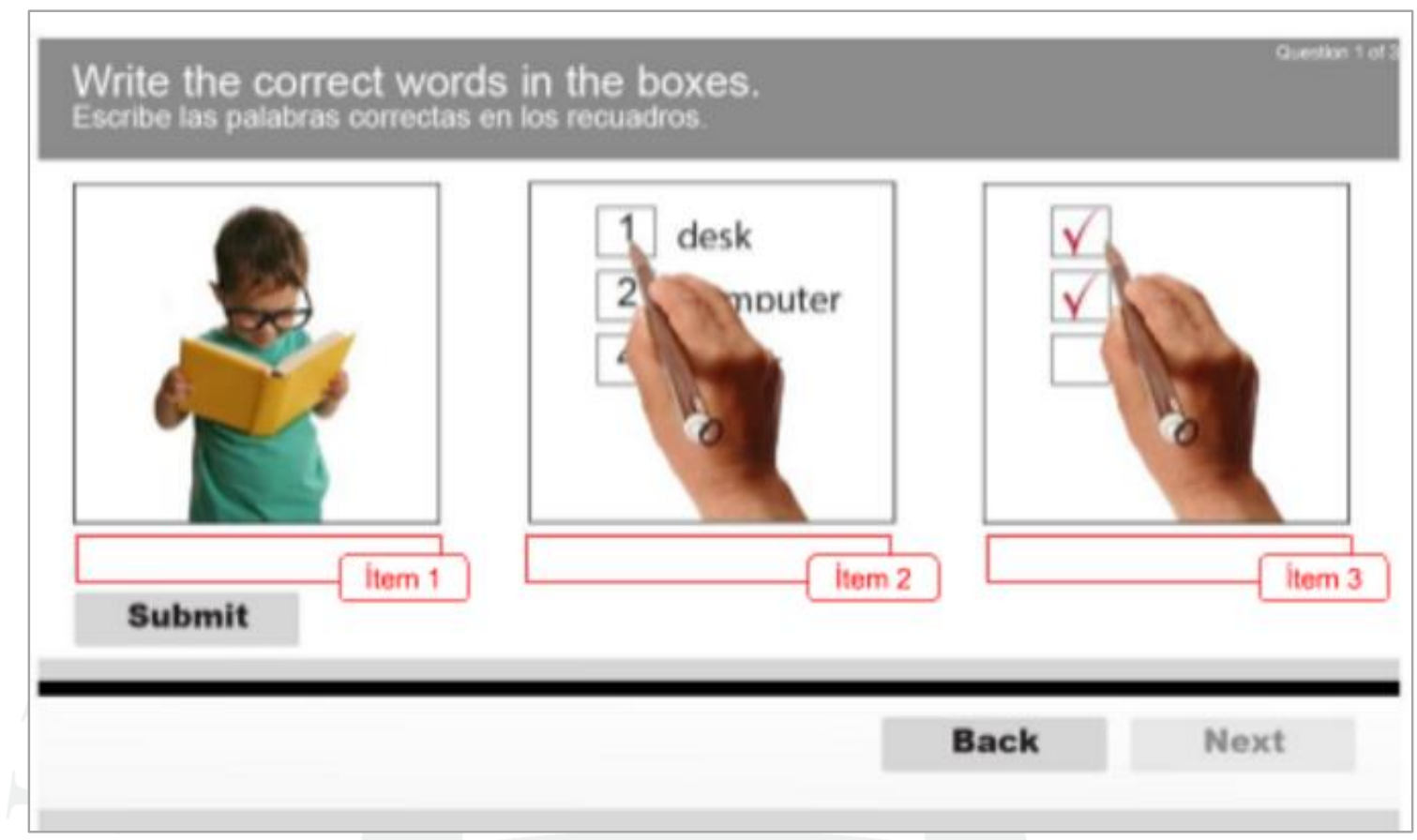

Figura 3: Una pantalla de evaluación con tres ítems para completar

Un error grave en la herramienta es que, en ciertas actividades que tienen varios ítems a ser respondidos (Ver Figura 3), no se precisan los errores puntuales de los alumnos, sino que se anula la respuesta completa si se comete al menos un error. Se le ofrece al usuario la posibilidad de volver a intentarlo, pero si nunca conoció en qué ítem tuvo el error, no sabrá cómo corregirlo. Esto genera un sentimiento de frustración y disminuye la utilidad percibida. Como mencionan Chandra y Yin (2009), una retroalimentación precisa es fundamental en los sistemas de aprendizaje virtual, ya que el alumno se encuentra normalmente solo frente a la herramienta. Asimismo, el acceso a las respuestas esperadas al finalizar las evaluaciones no es claro para los alumnos. La mayoría de ellos piensa que la herramienta no brinda las respuestas correctas aunque sí lo hace. El problema es que el botón que dirige a los alumnos a esa opción está en inglés y no llama la atención de los usuarios en esa pantalla, ya que existe otro botón que dice "Continue" para terminar de usar la herramienta.

Con respecto a la satisfacción, casi todos los participantes se encuentran satisfechos con la herramienta a pesar de las observaciones que fueron realizadas. Los 
usuarios indican que es provechosa y que reúne los temas vistos en clase con los que pueden seguir practicando. Es importante también el hecho de que los alumnos indicaron que querían seguir usando la herramienta en otros cursos que lleven, ya que esto denota una imagen positiva de la experiencia con el contenido. Igualmente, positivo es el hecho de que expresen que recomendarían usarla a otros de sus compañeros. Todo esto impacta positivamente en la usabilidad integral, como explica Nielsen (2003), la satisfacción es un componente que no debe ser dejado de lado cuando se evalúa la usabilidad. Esta idea también está reforzada por lo indicado en la norma ISO 9241, en su décimo primera parte [1998] (citado en Reyes y Libreros, 2011, p. 70):

"Entendemos por usabilidad a la magnitud en la que un producto puede ser utilizado por usuarios específicos para alcanzar ciertas metas con efectividad, eficiencia y satisfacción en un contexto específico de uso".

Expuestos todos estos puntos es conveniente considerar que la herramienta de aprendizaje virtual en cuestión cuenta con una usabilidad integral percibida por la mayoría de los participantes como adecuada y aceptable, ya que conjuga su facilidad de uso, utilidad y satisfacción provista a los usuarios, para brindar una experiencia de uso satisfactoria en la mayoría de los casos. No obstante, puede admitir cambios o mejoras que impactarán en la usabilidad integral para un mayor número de usuarios.

En estudios futuros, se puede investigar cómo el propósito de la herramienta puede afectar su usabilidad. Por ejemplo, si el ICPNA Mall no estuviera destinado al repaso y reforzamiento, sino a ser una solución de aprendizaje invertido en la que los alumnos se preparan con la teoría antes de la clase y realizan la práctica en el aula (Khalil y Fahim, 2016), es posible que la percepción de utilidad varíe y con ello el nivel de usabilidad integral.

\section{Recomendaciones}

- Es necesario basarse en las opiniones de los usuarios para poder incrementar la usabilidad integral percibida, y aunque la mayoría se sienta cómoda y a gusto con la herramienta, es importante también prestar oídos a las necesidades de grupos 
determinados de alumnos que tal vez no tengan la experiencia en plataformas virtuales de aprendizaje o incluso en entornos de internet.

- $\quad$ Es posible agregar un manual de uso corto para la herramienta, un video tutorial o un tutorial interactivo que los alumnos puedan aprovechar sobre todo la primera vez que ingresan al sistema. Luego el material puede permanecer como guía y fuente de consulta en caso se encuentren con alguna dificultad.

- $\quad$ No todas las dificultades van a ser cubiertas por un manual, por lo que es considerablemente importante proveer al alumno con información de contacto del encargado de la administración del contenido. Esto puede mejorar la percepción del alumno en cuanto al atributo de soporte, que es necesario para sentirse asesorado y considerar más llevadera la labor de usar la herramienta.

- $\quad$ Es necesario incrementar el número de ejercicios para que los usuarios no sientan que se encuentran frente a una evaluación muy sencilla o que no cubre todo el contenido. En general, los usuarios señalan una cantidad de entre quince y veinte como la adecuada.

- Se debe tomar las precauciones del caso en los escenarios en que se manejan varios ítems de pregunta por pantalla, ya que el sistema no brinda una retroalimentación específica por cada ítem sino por toda la pantalla. Se podría separar los ítems en distintas pantallas o generar una retroalimentación con todas las respuestas correctas por pantalla, para que sean visibles al alumno cuando se equivoca.

- $\quad$ Es importante resaltar el botón de revisar respuestas, que permite a los alumnos ver todas las respuestas correctas de la evaluación, ya que ahora pasa desapercibido y es beneficioso para los usuarios poder corregir sus errores.

\section{REFERENCIAS}

Araya, V., Alfaro, M. y Andonegui, M. (2007). Constructivismo: orígenes y perspectivas. Laurus Revista de Educación. 24(13), 76-92. 
Ardito, C., De Marsico, M., Lanzilotti, R., Levialdi, S., Roselli, T., Rossano, V. \& Tersigni, M. (2004). Usability of E-Learning Tools. In Proc. of International Conference on Advanced Visual Interface in Gallipoli, Italy. New York: ACM Press: 80-84.

Benbunan-Fich, R. (2001). Using protocol analysis to evaluate the usability of a commercial web site. Information and Management, 39, 151-163.

Botturi, L., Cantoni, L., Inversini, A., \& Succi, C. (2007). Sustainable eLearning quality: A lightweight method from experience. In N. Buzzetto-More (Ed.), Advanced Principles of Effective eLearning, Hershey, PA: Idea Group: 161-183.

Británico (2015) Sitio Web. Recuperado el 15 de febrero de 2017 de http://www.britanico.edu.pe/programa/e-learning/britanico-blended-bb/

Chandra, S., y Yin Leng, T. (2009). Usability Evaluation of Game-based E-Learning Systems. International Journal Of Global Management Studies Professional, 1(3), 40-54.

Christensen, C. (1997). The Innovators Dilemma: when new technologies cause great firms to Fail. Boston, Ma. Harvard Business School Press.

Davids, M. m., Chikte, U. E., y Halperin, M. L. (2014). Effect of improving the usability of an e-learning resource: a randomized trial. Advances In Physiology Education, 38(2), 155-160.

Euroidiomas (2015). Sitio Web. Recuperado el 15 de febrero de 2017 de https://euroidiomas.edu.pe/ingles-general-virtual/

Ertmer, P. A., \& Newby, T. J. (2013). Behaviorism, cognitivism, constructivism: Comparing critical features from an instructional design perspective. Performance Improvement Quarterly, 26(2), 43-71.

GhalibAI-Masoudi, M y Chandrashekara, M (2010) Usability Satisfaction of Open Source eLearning Courseware Websites. Journal of Information Science and Technology, 7 (s) pp. 21-35

Guilar, Moisés Esteban. (2009). Las ideas de Bruner: "de la revolución cognitiva" a la "revolución cultural". Educere, 13(44), 235-241.

Hernández, R., Fernández, C., Baptista, P. (2006). Metodología de la Investigación. (4 ${ }^{\mathrm{a}}$ Ed.) Mexico D. F.: McGraw Hill 
Idiomas Católica (2015). Sitio Web. Recuperado el 15 de febrero de 2017 de http://idiomas.pucp.edu.pe/programas/cursos-virtuales/curso-de-ingles/

Khalil, R. R., \& Fahim, S. S. (2016). Assessment as a Learning Tool in a Flipped English Language Classroom in Higher Education. Arab World English Journal, 7(4), 4-19.

Krug, S (2000). Don't make me think: A common sense approach to web usability, Indianapolis (IN): New Riders.

Mvududu NH \& Thiel-Burgess J. 2012. Constructivism in Practice: The Case for English Language Learners. International Journal of Education, 4(3), p108p118.

Nielsen, J (2003, 25 de Agosto). Usability 101: Introduction to Usability.

Recuperado el 21 de Mayo de 2015 de

http://www.nngroup.com/articles/usability-101-introduction-to-usability/

Notess, M. (2001, Agosto). Usability, user experience, and learner experience.

Elearn magazine, 2001(8). Recuperado el 21 de Mayo de 2015 de http://elearnmag.acm.org/archive.cfm?aid=566938

Reyes Vera, J. M., y Libreros Giraldo, F. A. (2011). Método para la evaluación integral de la usabilidad en sistemas e-learning. Revista Educación en Ingeniería, (12), 69-79.

Schneiderman, B (1998). Designing the user interface: strategies for effective human-computer-interaction (3ra Ed.) Reading, Mass: Addison Wesley.

Triacca, L., Bolchini, D., Botturi, L. \& Inversini, A. (2004). MiLE: Systematic Usability Evaluation for E-learning Web Applications. In L. Cantoni \& C. McLoughlin (Eds.), Proceedings of World Conference on Educational Multimedia, Hypermedia and Telecommunications: Chesapeake, VA: AACE: 4398-4405.

Tünnermann, C. (2011). El constructivismo y el aprendizaje de los estudiantes. Universidades. LXI (48), 21-32.

Zaharias, P. A. (2009). Developing a Usability Evaluation Method for e-Learning Applications: Beyond Functional Usability. International Journal Of Human-Computer Interaction, 25(1), 75-98. 


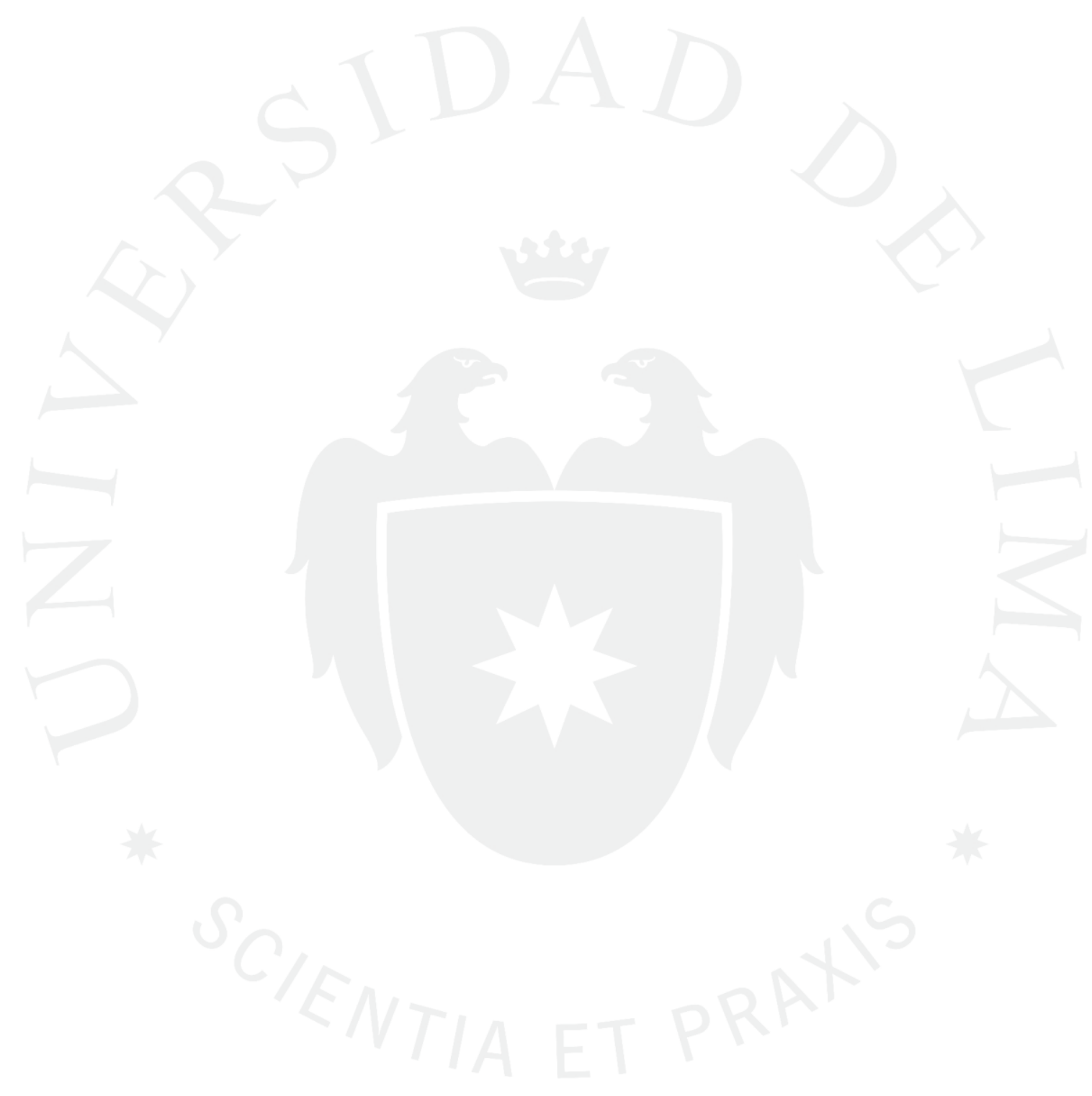


ANEXOS 


\section{ANEXO 1: Matriz de entrevistas}

\begin{tabular}{|c|c|c|c|c|c|}
\hline & & & & & \\
\hline & $\mathbf{A H}$ & $\mathbf{A P}$ & $\mathbf{R A}$ & $\mathbf{A C}$ \\
\hline \multirow{5}{*}{$\begin{array}{l}\text { Facilidad } \\
\text { de Uso }\end{array}$} & Diseño Visual & $\begin{array}{l}\text { Comprensibl } \\
\text { e / Adaptable } \\
\text { (inglés- } \\
\text { español) }\end{array}$ & $\begin{array}{l}\text { Comprensible/ } \\
\text { Adaptable } \\
\text { (idiomas) / } \\
\text { énfasis/ opaco }\end{array}$ & Comprensible & $\begin{array}{l}\text { Comprensible } \\
\text { / Atractivo }\end{array}$ \\
\hline & Funcionalidad & $\begin{array}{l}\text { Botones } \\
\text { reconocibles } \\
\text { y funcionales } \\
\text { / Carga } \\
\text { rápida }\end{array}$ & $\begin{array}{l}\text { Botones } \\
\text { reconocibles y } \\
\text { funcionales }\end{array}$ & $\begin{array}{l}\text { Botones } \\
\text { reconocibles y } \\
\text { funcionales / } \\
\text { Carga rápida }\end{array}$ & $\begin{array}{l}\text { Botones } \\
\text { reconocibles y } \\
\text { funcionales / } \\
\text { Carga rápida }\end{array}$ \\
\hline & Soporte & No indica & $\begin{array}{l}\text { No indica / No } \\
\text { necesita } \\
\text { manual }\end{array}$ & $\begin{array}{l}\text { No indica / No } \\
\text { necesita } \\
\text { manual }\end{array}$ & $\begin{array}{l}\text { No indica / } \\
\text { Necesita video } \\
\text { tutorial }\end{array}$ \\
\hline & Navegabilidad & $\begin{array}{l}\text { Progreso } \\
\text { visible } \\
\text { (LMS) / } \\
\text { Navegación } \\
\text { por botones } \\
\text { clara }\end{array}$ & $\begin{array}{l}\text { Progreso } \\
\text { visible (LMS) } \\
\text { / Navegación } \\
\text { por botones } \\
\text { clara }\end{array}$ & $\begin{array}{l}\text { Progreso } \\
\text { visible (LMS) } \\
\text { / Navegación } \\
\text { por botones } \\
\text { clara }\end{array}$ & $\begin{array}{l}\text { Progreso } \\
\text { visible (LMS) } \\
\text { / Navegación } \\
\text { por botones } \\
\text { clara }\end{array}$ \\
\hline & $\begin{array}{l}\text { Facilidad de } \\
\text { Uso General }\end{array}$ & Muy fácil & Fácil & Muy fácil & Muy fácil \\
\hline \multirow{4}{*}{ Utilidad } & Contenido & $\begin{array}{l}\text { Adaptable } \\
\text { (idiomas) / } \\
\text { Comprensibl } \\
\text { e / Refuerzo / } \\
\text { Correspondie } \\
\text { nte }\end{array}$ & $\begin{array}{l}\text { Adaptable } \\
\text { (idiomas) / } \\
\text { Correspondien } \\
\text { te / } \\
\text { Comprensible } \\
\text { / Falta de } \\
\text { ejemplos / } \\
\text { Faltan } \\
\text { Ejercicios } \\
\end{array}$ & $\begin{array}{l}\text { Correspondien } \\
\text { te / } \\
\text { Comprensible } \\
\text { / Refuerzo }\end{array}$ & $\begin{array}{l}\text { Correspondien } \\
\text { te / Poco } \\
\text { comprensible }\end{array}$ \\
\hline & Evaluación & $\begin{array}{l}\text { Comprensibl } \\
\text { e / Adecuada }\end{array}$ & $\begin{array}{l}\text { Comprensible } \\
\text { / Insuficiente }\end{array}$ & $\begin{array}{l}\text { Insuficiente / } \\
\text { Comprensible } \\
\text { / } \\
\text { Correspondien } \\
\text { te }\end{array}$ & $\begin{array}{l}\text { Comprensible } \\
\text { / Refuerzo }\end{array}$ \\
\hline & $\begin{array}{l}\text { Retroalimenta } \\
\text { ción }\end{array}$ & $\begin{array}{l}\text { No da } \\
\text { respuestas / } \\
\text { Varios } \\
\text { intentos }\end{array}$ & $\begin{array}{l}\text { No da } \\
\text { respuestas }\end{array}$ & $\begin{array}{l}\text { Comentarios } \\
\text { por respuesta / } \\
\text { No da } \\
\text { respuestas / } \\
\text { Pistas }\end{array}$ & $\begin{array}{l}\text { Todo o nada } \\
\text { por pantalla }\end{array}$ \\
\hline & $\begin{array}{l}\text { Utilidad } \\
\text { General }\end{array}$ & Útil & Útil & Muy útil & Muy útil \\
\hline \multicolumn{2}{|c|}{ Satisfacción } & $\begin{array}{l}\text { Muy } \\
\text { satisfecha }\end{array}$ & $\begin{array}{l}\text { Algo } \\
\text { insatisfecha }\end{array}$ & $\begin{array}{l}\text { Muy } \\
\text { satisfecho }\end{array}$ & $\begin{array}{l}\text { Muy } \\
\text { satisfecho }\end{array}$ \\
\hline
\end{tabular}




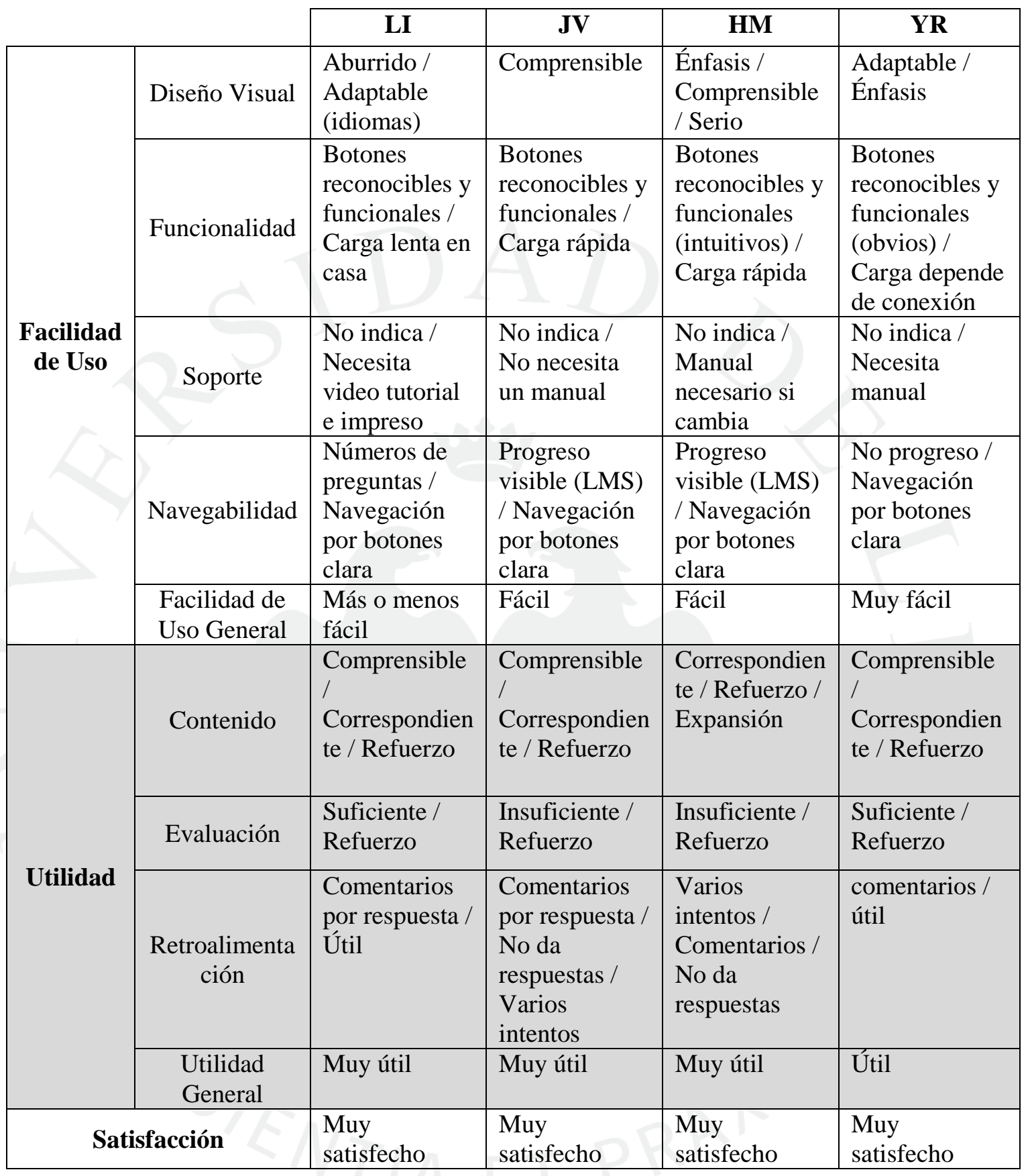




\begin{tabular}{|c|c|c|c|c|c|}
\hline & & & & \\
\hline & & AI & $\overline{V C}$ & CR & LG \\
\hline \multirow{5}{*}{$\begin{array}{c}\text { Facilidad } \\
\text { de Uso }\end{array}$} & Diseño Visual & $\begin{array}{l}\text { Comprensibl } \\
\mathrm{e}\end{array}$ & $\begin{array}{l}\text { Aburrido / } \\
\text { Comprensible }\end{array}$ & $\begin{array}{l}\text { Comprensible } \\
\text { / Adaptable } \\
\text { (idiomas) }\end{array}$ & $\begin{array}{l}\text { Comprensible } \\
\text { / Adaptable }\end{array}$ \\
\hline & Funcionalidad & $\begin{array}{l}\text { Botones } \\
\text { reconocibles } \\
\text { y funcionales } \\
\text { / Carga } \\
\text { rápida }\end{array}$ & $\begin{array}{l}\text { Botones } \\
\text { reconocibles y } \\
\text { funcionales / } \\
\text { Consistentes / } \\
\text { Carga depende } \\
\text { de conexión }\end{array}$ & $\begin{array}{l}\text { Botones } \\
\text { reconocibles y } \\
\text { funcionales / } \\
\text { Carga rápida }\end{array}$ & $\begin{array}{l}\text { Botones } \\
\text { reconocibles y } \\
\text { funcionales / } \\
\text { Carga lenta }\end{array}$ \\
\hline & Soporte & $\begin{array}{l}\text { No indica / } \\
\text { No necesita } \\
\text { manual }\end{array}$ & $\begin{array}{l}\text { No indica / } \\
\text { Necesita video } \\
\text { tutorial }\end{array}$ & $\begin{array}{l}\text { No indica / } \\
\text { Necesita } \\
\text { manual }\end{array}$ & $\begin{array}{l}\text { No indica / No } \\
\text { necesita } \\
\text { manual }\end{array}$ \\
\hline & Navegabilidad & $\begin{array}{l}\text { No progreso / } \\
\text { Navegación } \\
\text { por botones } \\
\text { clara }\end{array}$ & $\begin{array}{l}\text { Números de } \\
\text { preguntas / } \\
\text { Navegación } \\
\text { por botones } \\
\text { clara }\end{array}$ & $\begin{array}{l}\text { Progreso } \\
\text { visible (LMS) } \\
\text { / Navegación } \\
\text { por botones } \\
\text { clara }\end{array}$ & $\begin{array}{l}\text { Progreso } \\
\text { visible (LMS) } \\
\text { / Navegación } \\
\text { por botones } \\
\text { clara }\end{array}$ \\
\hline & $\begin{array}{l}\text { Facilidad de } \\
\text { Uso General }\end{array}$ & Muy fácil & Fácil & $\begin{array}{l}\text { Difícil al } \\
\text { inicio }\end{array}$ & Muy fácil \\
\hline \multirow{4}{*}{ Utilidad } & Contenido & $\begin{array}{l}\text { Comprensibl } \\
\text { e / } \\
\text { Correspondie } \\
\text { nte / } \\
\text { Refuerzo }\end{array}$ & $\begin{array}{l}\text { Comprensible } \\
\text { / } \\
\text { Correspondien } \\
\text { te / Refuerzo }\end{array}$ & $\begin{array}{l}\text { Comprensible } \\
\text { / } \\
\text { Correspondien } \\
\text { te / Refuerzo }\end{array}$ & $\begin{array}{l}\text { Comprensible } \\
\text { / } \\
\text { Correspondien } \\
\text { te / Refuerzo }\end{array}$ \\
\hline & Evaluación & $\begin{array}{l}\text { Insuficiente / } \\
\text { Refuerzo }\end{array}$ & $\begin{array}{l}\text { Suficiente / } \\
\text { Refuerzo }\end{array}$ & $\begin{array}{l}\text { Suficiente / } \\
\text { Refuerzo }\end{array}$ & $\begin{array}{l}\text { Insuficiente / } \\
\text { Refuerzo }\end{array}$ \\
\hline & $\begin{array}{l}\text { Retroalimenta } \\
\text { ción }\end{array}$ & $\begin{array}{l}\text { comentarios / } \\
\text { no da } \\
\text { respuesta } \\
\text { correcta / útil } \\
\text { / pistas }\end{array}$ & $\begin{array}{l}\text { No da } \\
\text { respuestas / } \\
\text { inútil }\end{array}$ & $\begin{array}{l}\text { Pistas / } \\
\text { Respuestas al } \\
\text { final }\end{array}$ & $\begin{array}{l}\text { No da } \\
\text { respuestas / } \\
\text { No intentos }\end{array}$ \\
\hline & $\begin{array}{l}\text { Utilidad } \\
\text { General }\end{array}$ & Útil & Muy útil & Muy útil & Muy útil \\
\hline \multicolumn{2}{|c|}{ Satisfacción } & $\begin{array}{l}\text { Algo } \\
\text { satisfecho }\end{array}$ & Neutral & $\begin{array}{l}\text { Algo } \\
\text { satisfecha }\end{array}$ & $\begin{array}{l}\text { Muy } \\
\text { satisfecha }\end{array}$ \\
\hline
\end{tabular}




\begin{tabular}{|c|c|c|c|c|}
\hline & & & \\
\hline & & $\mathbf{K S}$ & $\mathrm{CV}$ & $\mathbf{A C}$ \\
\hline \multirow{5}{*}{$\begin{array}{c}\text { Facilidad } \\
\text { de Uso }\end{array}$} & Diseño Visual & $\begin{array}{l}\text { Agradable / } \\
\text { Adaptable }\end{array}$ & $\begin{array}{l}\text { Agradable / } \\
\text { Aburrido }\end{array}$ & $\begin{array}{l}\text { Adaptable / } \\
\text { Agradable }\end{array}$ \\
\hline & Funcionalidad & $\begin{array}{l}\text { Botones } \\
\text { reconocibles y } \\
\text { funcionales / } \\
\text { carga rápida }\end{array}$ & $\begin{array}{l}\text { Botones } \\
\text { reconocibles y } \\
\text { funcionales }\end{array}$ & $\begin{array}{l}\text { Botones } \\
\text { reconocibles y } \\
\text { funcionales / } \\
\text { Carga rápida }\end{array}$ \\
\hline & Soporte & $\begin{array}{l}\text { No indica / No } \\
\text { necesita manual }\end{array}$ & $\begin{array}{l}\text { No indica / } \\
\text { Necesita manual } \\
\text { en texto }\end{array}$ & $\begin{array}{l}\text { No indica / No } \\
\text { necesita manual }\end{array}$ \\
\hline & Navegabilidad & $\begin{array}{l}\text { No progreso / } \\
\text { Navegación por } \\
\text { botones clara }\end{array}$ & $\begin{array}{l}\text { Progreso visible } \\
\text { (LMS) / } \\
\text { Navegación por } \\
\text { botones clara }\end{array}$ & $\begin{array}{l}\text { Progreso visible } \\
\text { (LMS) / } \\
\text { Navegación por } \\
\text { botones clara }\end{array}$ \\
\hline & $\begin{array}{c}\text { Facilidad de Uso } \\
\text { General }\end{array}$ & Fácil & Poco difícil & Fácil \\
\hline \multirow{4}{*}{ Utilidad } & Contenido & $\begin{array}{l}\text { Comprensible / } \\
\text { Correspondiente / } \\
\text { Refuerzo }\end{array}$ & $\begin{array}{l}\text { Comprensible / } \\
\text { Correspondiente / } \\
\text { refuerzo }\end{array}$ & $\begin{array}{l}\text { Comprensible / } \\
\text { Correspondiente }\end{array}$ \\
\hline & Evaluación & $\begin{array}{l}\text { Insuficiente / } \\
\text { Refuerzo }\end{array}$ & $\begin{array}{l}\text { Insuficiente / } \\
\text { Refuerzo }\end{array}$ & $\begin{array}{l}\text { Insuficiente / } \\
\text { Correspondiente }\end{array}$ \\
\hline & Retroalimentación & Todo o nada & Útil & $\begin{array}{l}\text { Útil / Varios } \\
\text { intentos }\end{array}$ \\
\hline & Utilidad General & Muy útil & Útil & Muy útil \\
\hline \multicolumn{2}{|c|}{ Satisfacción } & Muy satisfecha & Algo satisfecho & Satisfecho \\
\hline
\end{tabular}


ANEXO 2: Matriz de entrevistas con contabilización de términos usados

\begin{tabular}{|c|c|c|c|c|c|c|c|c|c|c|c|c|c|c|c|c|c|}
\hline & & & $\frac{\pi}{4}$ & 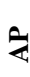 & $\widetilde{\varepsilon}$ & U & ב & Z & $\sum$ & $\stackrel{x}{\lambda}$ & Z & $\underset{D}{Z}$ & ชี & ב્ּ & $\approx$ & 己 & U \\
\hline & & Comprensible & 1 & 1 & 1 & 1 & & 1 & 1 & & 1 & 1 & 1 & 1 & & & \\
\hline & & Adaptable & 1 & 1 & & & 1 & & & 1 & & & 1 & 1 & 1 & & 1 \\
\hline & & Énfasis & & 1 & F & & & & 1 & 1 & & & & & & & \\
\hline & $i^{2}$ & Atractivo & & & & 1 & & & & & & & & & & & \\
\hline & 产 & Aburrido & & & 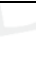 & & 1 & & 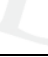 & 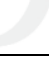 & & 1 & & & & 1 & \\
\hline & $\ddot{a}$ & Serio & & & & & & & 1 & & & & & & & & \\
\hline & & Opaco & & 1 & & & & & & & & & & & & & \\
\hline & & Agradable & & & & & & & & & & & & & 1 & 1 & 1 \\
\hline & $\underset{Z}{\tilde{J}}$ & $\begin{array}{l}\text { Btns. reconoc. } \mathrm{y} \\
\text { func. }\end{array}$ & 1 & 1 & 1 & 1 & 1 & 1 & 1 & 1 & 1 & 1 & 1 & 1 & 1 & 1 & 1 \\
\hline & $\bar{\Xi}$ & Carga rápida & 1 & & 1 & 1 & & 1 & 1 & & 1 & & 1 & & 1 & & 1 \\
\hline & שֶ & Carga lenta & & & & & 1 & & & & & & & 1 & & & \\
\hline & 可 & Carga depende & & & & & & & & 1 & & 1 & & & & & \\
\hline$\overline{0}$ & & No indica & 1 & 1 & 1 & 1 & 1 & 1 & 1 & 1 & 1 & 1 & 1 & 1 & 1 & 1 & 1 \\
\hline ت & $\stackrel{\mathscr{V}}{\mathscr{V}}$ & $\begin{array}{c}\text { No necesita } \\
\text { manual }\end{array}$ & & 1 & 1 & & & 1 & 1 & & 1 & & & 1 & 1 & & 1 \\
\hline :" & $\begin{array}{l}\text { ڤे } \\
\text { है }\end{array}$ & $\begin{array}{c}\text { Necesita Video } \\
\text { Tutorial }\end{array}$ & & & & 1 & 1 & & & & & 1 & & & & & \\
\hline & & $\begin{array}{c}\text { Necesita } \\
\text { manual texto }\end{array}$ & & & & & 1 & & & 1 & & & 1 & & & 1 & 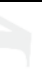 \\
\hline & T్త్ర & $\begin{array}{c}\text { Progreso } \\
\text { Visible en LMS }\end{array}$ & 1 & 1 & 1 & 1 & & 1 & 1 & & & & 1 & 1 & & 1 & 1 \\
\hline & 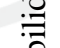 & No progreso & & & & & & & & 1 & 1 & & & & 1 & & \\
\hline & $\begin{array}{l}\vec{\pi} \\
\stackrel{0}{0} \\
己\end{array}$ & $\begin{array}{l}\text { Nav. por btns. } \\
\text { clara }\end{array}$ & 1 & 1 & 1 & 1 & 1 & 1 & 1 & 1 & 1 & 1 & 1 & 1 & 1 & 1 & 1 \\
\hline & Z & $\begin{array}{c}\text { Números de } \\
\text { preg. }\end{array}$ & & & & & 1 & & & & & 1 & & & 4 & & \\
\hline & 0 & Muy fácil & 1 & & 1 & 1 & & & & 1 & 1 & & & 1 & & & \\
\hline & 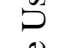 & Fácil & & 1 & & & & 1 & 1 & & & 1 & & & 1 & & 1 \\
\hline & $\frac{\pi}{7}$ & $\begin{array}{l}\text { Más o menos } \\
\text { fácil }\end{array}$ & & & & & 1 & & & & & & 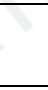 & & & & \\
\hline & তृ & Difícil al inicio & & & . & & t & r & & & 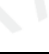 & & 1 & & & & \\
\hline & & Algo difícil & & & & & & & & & & & & & & 1 & \\
\hline & & Adaptable & 1 & 1 & & & & & & & & & & & & & \\
\hline & & Comprensible & 1 & 1 & 1 & & 1 & 1 & & 1 & 1 & 1 & 1 & 1 & 1 & 1 & 1 \\
\hline శ్రే & $\frac{0}{\frac{0}{\pi}}$ & $\begin{array}{c}\text { Correspondient } \\
\mathrm{e} \\
\end{array}$ & 1 & 1 & 1 & 1 & 1 & 1 & 1 & 1 & 1 & 1 & 1 & 1 & 1 & 1 & 1 \\
\hline 疋 & $\ddot{\Xi}$ & Refuerzo & 1 & & 1 & & 1 & 1 & 1 & 1 & 1 & 1 & 1 & 1 & 1 & 1 & \\
\hline & & Expansión & & & & & & & 1 & & & & & & & & \\
\hline & & $\begin{array}{c}\text { Poco } \\
\text { comprensible }\end{array}$ & & & & 1 & & & & & & & & & & & \\
\hline
\end{tabular}




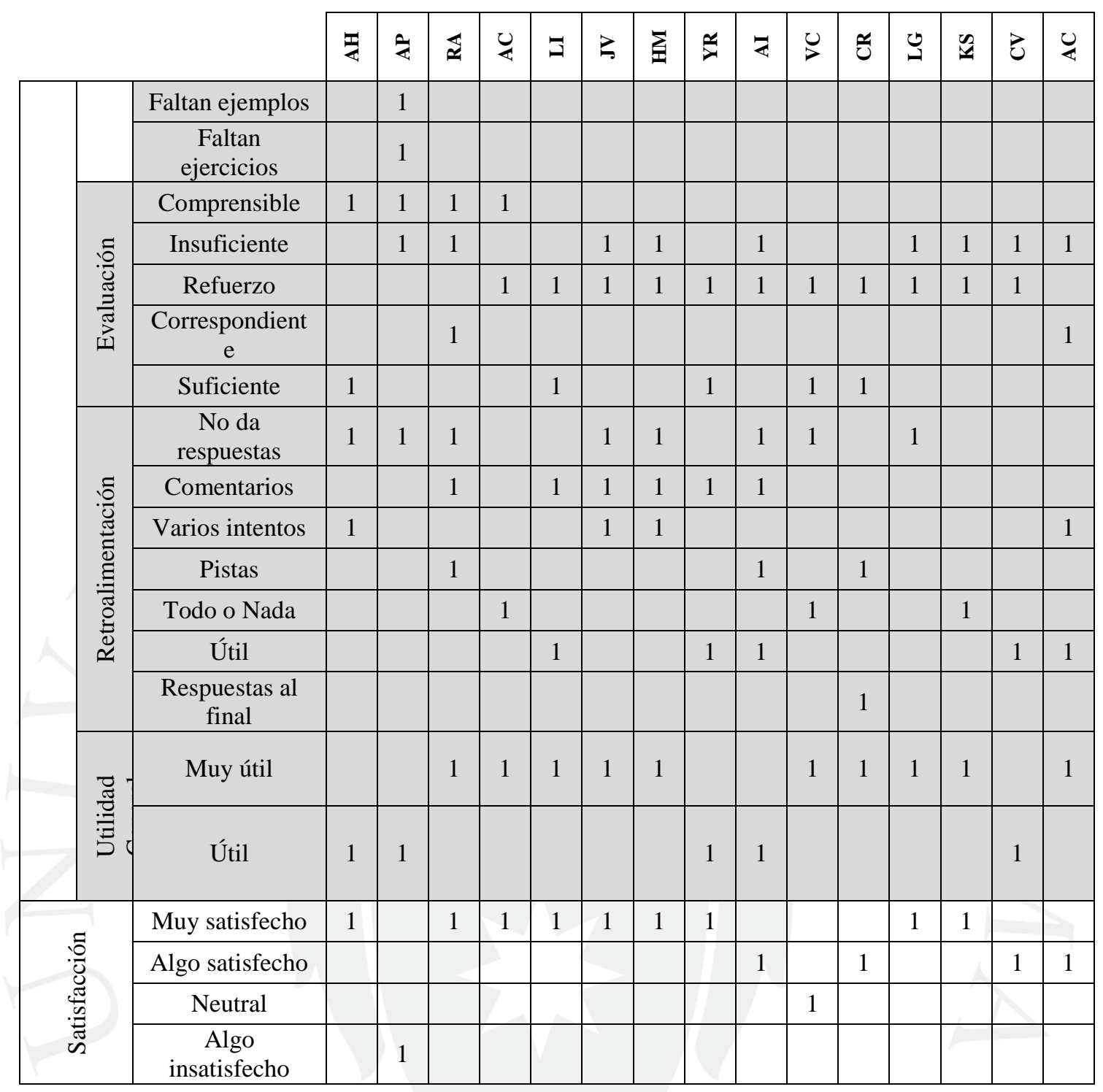




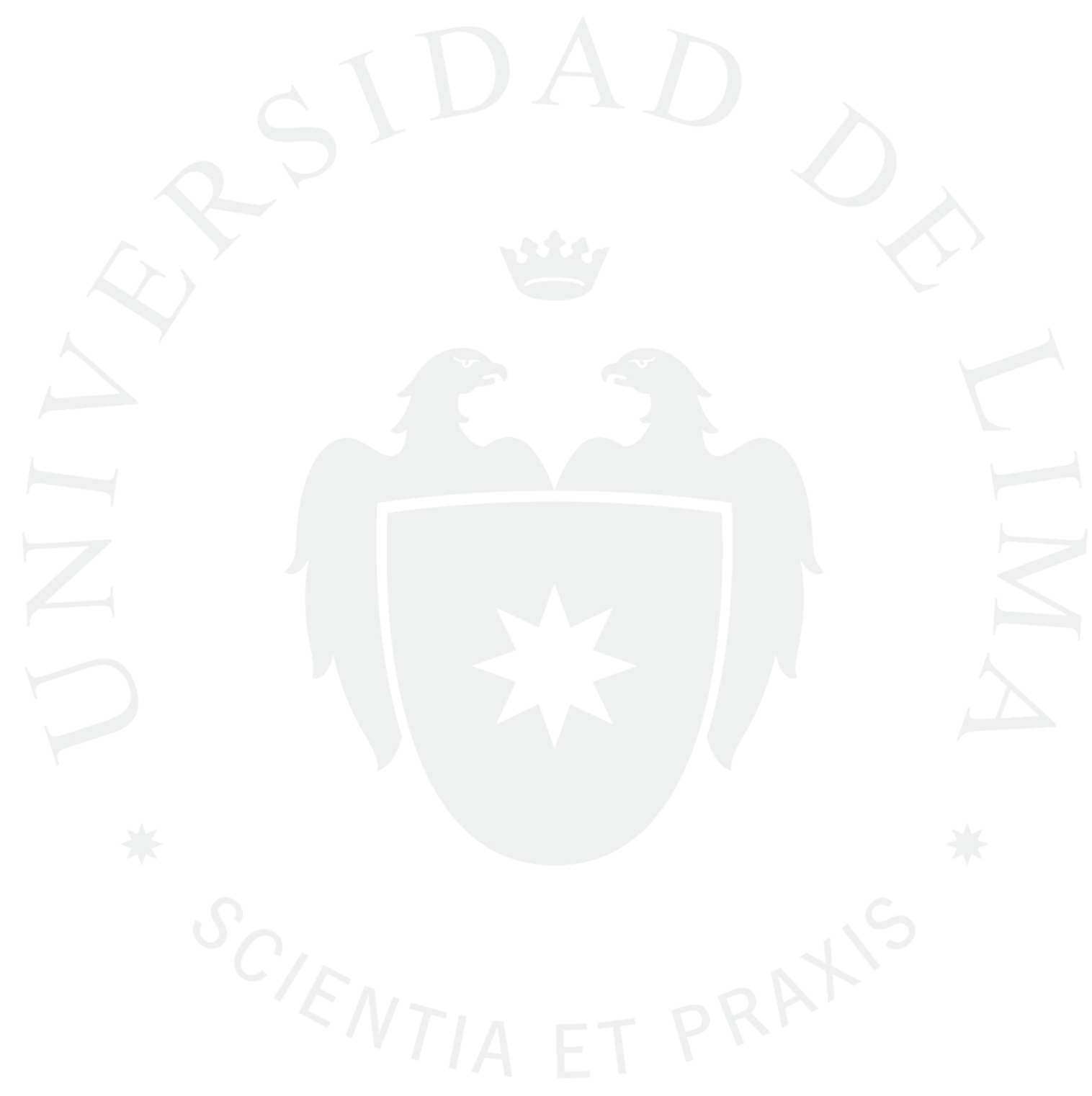




\section{ÍNDICE DE TABLAS}

Tabla 1: Ficha metodológica. 8

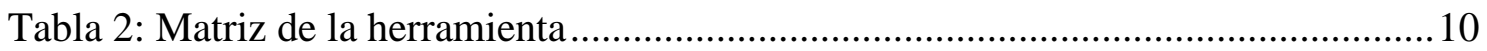

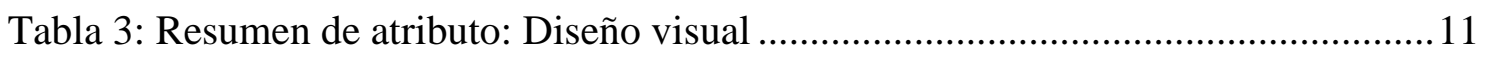

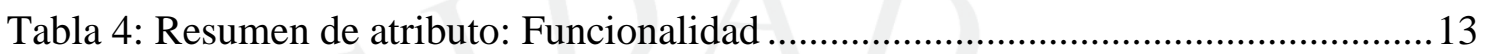

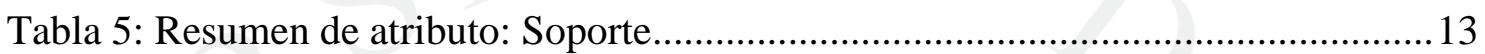

Tabla 6: Resumen de atributo: Navegabilidad......................................................... 14

Tabla 7: Resumen de atributo: Facilidad de uso general ................................................ 16

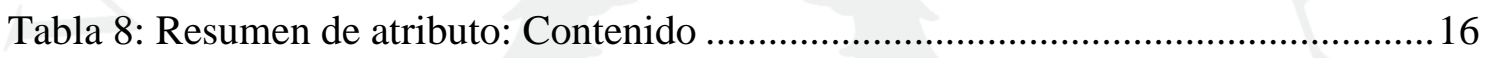

Tabla 9: Resumen de atributo: Evaluación .......................................................... 18

Tabla 10: Resumen de atributo: Retroalimentación ................................................. 19

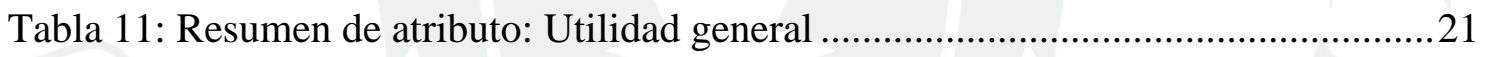

Tabla 12: Resumen de atributo: Satisfacción general ....................................................21 


\section{ÍNDICE DE FIGURAS}

Figura 1: Una pantalla de presentación de lección

Figura 2: Una pantalla de evaluación con tres ítems para completar 20

Figura 3: Una pantalla de evaluación con tres ítems para completar .26 